ESTUDIOS 



\section{1. \\ Derecho privado}





\title{
LA EXPOSICIÓN DE LA VÍCTIMA AL DAÑO: DESDE LA CULPABILIDAD A LA CAUSALIDAD*
}

["Victim Exposed to Damage: From Culpability to Causality"]

\author{
Claudia Bahamondes O.** \\ Universidad Diego Portales, Santiago de Chile \\ Carlos Pizarro W.*** \\ Universidad Diego Portales, Santiago de Chile
}

RESUMEN

Son variados los problemas asociados a la exposición de la víctima al daño partiendo del entendimiento del artículo 2330 del Código civil. Su fundamento parte de la exigencia de autocuidado de las víctimas, cuyo comportamiento se modela en torno al deber análogo a no dañar al prójimo, siendo delicado dilucidar en qué forma se debe considerar la situación de los incapaces, los herederos y las víctimas por rebote, cuya fisonomía sólo se entrelaza a través de la causalidad.

Palabras clave

Exposición de la víctima - Responsabilidad civil - Causalidad.
Abstract

Article 2330 of the Code of Civil Procedure poses several problems regarding the victim's exposure to damage. This article is based on the requirement that victims must practice self-care, whose behavior is modeled around the similar duty of not harming our neighbor. Determining how to consider the situation of the handicapped, heirs and victims by ricochet, which physiognomy is merely entangled by means of causality, is a highly sensitive matter.

\section{KEYWORDS}

Victim's exposure - Civil liability Causality.

RECIBIDO el 20 de septiembre y APROBADo el 1 de octubre de 2012.

* Este artículo forma parte del proyecto FondeCYT regular, titulado: "Finalidad, contenido y extensión de la indemnización de daños”, dirigido por el profesor Álvaro Vidal Olivares.

** Profesora de Derecho Civil de la Universidad Diego Portales. Candidata a doctor en Derecho por la Pontificia Universidad Católica de Valparaíso. Dirección postal: República 112, Santiago, Chile. Correo electrónico: claudia.bahamondes@udp.cl

*** Profesor investigador de la Facultad de Derecho de la Universidad Diego Portales, Santiago, Chile. Doctor en Derecho por la Universidad Paris II Panthéon-Assas. Dirección postal: República 112, Santiago, Chile. Correo electrónico: carlos.pizarro@ udp.cl 


\section{INTRODUCCIÓN}

La participación de la víctima en la causación de su propio daño no ha merecido los estudios necesarios si se considera su importancia práctica, ya sea para excluir la responsabilidad o para atenuar la indemnización reclamada. La responsabilidad civil suele analizarse en perspectiva de configuración de los elementos que hacen prosperar la indemnización. Mas esta mirada clásica es insuficiente si se considera que la actividad de la víctima puede tener consecuencias relevantes a la hora de otorgar, negar o reducir una indimnización de perjuicios.

Es usual que su estudio sea realizado a partir del artículo 2330 CC. ${ }^{1}$ Si la víctima ha participado en forma culpable en el resultado dañino, el juez debe reducir la indemnización. Sin embargo, la intervención de la víctima en las causas del daño o una vez ya producido en su agravación permiten realizar una mirada más amplia del fenómeno que circunscribirle a un problema de culpa, siendo en todos los casos un problema de causalidad en el daño lo que explica la rebaja en la indemnización o, debiera decirse de manera más correcta, que se paga nada más el perjuicio causado.

Hasta ahora los esfuerzos dogmáticos se han concetrado en el estudio de la regla ya citada en perspectiva de culpa, siendo en realidad un asunto de causalidad.

\section{LA PROCEDENCIA}

Entre las múltiples condiciones que concurren al momento de consumarse un ilícito civil, la intervención de los sujetos involucrados es imprescindible. La ocurrencia del daño requiere de alguna actividad o, al menos, de la presencia de la propia víctima. No obstante, dicha participación no debiera tener importancia al momento de atribuir la responsabilidad al autor del perjuicio, manteniéndose incólume la posibilidad de obtener una reparación íntegra de los menoscabos experimentados, pese a la innegable verificación de un hecho del afectado ${ }^{2}$.

${ }^{1}$ Alessandri Rodríguez, Arturo, De la responsabilidad extracontractual en el Derecho civil chileno (Santiago, 2005), pp. 412 ss.; Corral Talciani, Hernán, Lecciones de responsabilidad civil extracontractual (Santiago, 2004), pp. 200 ss.; Diez SCHWERTER, José Luis, El daño extracontractual. Jurisprudencia y doctrina (Santiago, 2002), pp. 225 ss. Un artículo original y temprano es el de Domínguez ÁGuila, R., El hecho de la victima como causal de exoneración de responsabilidad civil, en Revista de Derecho, 135 (Concepción, 1966), p. 29 ss.

${ }^{2}$ Barros Bourie, Enrique, Tratado de responsabilidad extracontractual (Santiago, 2009), pp. 427 y 428. 
Sin embargo, la situación cambia si la acción u omisión de la víctima es negligente; en este caso, la culpa del propio perjudicado que contribuye a la provocación del daño, acarreará repercusiones en la cuantía, siendo aplicable el artículo 2330 CC.

Con antecedentes directos en el artículo 2199 del ALPS. Prusiano $(1794)^{3}$, la referida regla obliga al juez a reducir la apreciación de los perjuicios si el afectado se expuso en forma imprudente al daño. Conforme con la redacción de la norma, parte importante de la doctrina ha estimado que se trata de una rebaja forzosa para el juez, no pudiendo eludir este imperativo si se verifica el supuesto de la norma ${ }^{4}$. Esta opinión parece adecuada siendo susceptible de casación la sentencia que no la acoja habiéndose acreditado la circunstancia que la hace procedente.

En ningún caso la regla admite la excusa del victimario, ni aun en caso de daños recíprocos, no pudiendo anularse las culpas mutuas 5 . En todo caso se trata de un efecto que incide en la cuantía del perjuicio mas no en su configuración.

Tampoco contempla una exoneración de responsabilidad provocada por la interrupción del vínculo causal, como ocurriría si la negligencia del

${ }^{3}$ Figueroa Yáñez, Gonzalo (redactor), Código Civil y leyes complementarias (2a edición, Santiago, 1998), X, p. 240.

${ }^{4}$ Alessandri, cit. (n. 1), pp. 414 y 415; Corral, cit. (n. 1), pp. 202 y 203; Diez, cit. (n. 1), p. 230. Esta situación difiere del actual sistema francés, pues la nueva redacción del artículo 706.3 del Code de procédure pénale, que contiene una norma similar a la regla chilena, señala que la reparación para quien haya sufrido perjuicios por infracciones y que resulten de atentados contra las personas, $\mathrm{p}$ u e d e ser rechazada o su valor reducido en razón de la culpa de la víctima: "Toute personne ayant subi un préjudice résultant de faits volontaires ou non qui présentent le caractère matériel d'une infraction peut obtenir la réparation intégrale des dommages qui résultent des atteintes à la personne, lorsque sont réunies les conditions suivantes : [...] La réparation peut être refusée ou son montant réduit à raison de la faute de la victime". Este marcado carácter facultativo de la regla no ha estado exento de críticas por parte de la doctrina, pues provoca una perniciosa apertura entre la negación absoluta de reparación y la disminución de la suma indemnizatoria, sin señalar los criterios necesarios para proceder a dicha opción. Viney, Geneviève, Tratado de derecho civil. Introducción a la responsabilidad (trad. cast. de Fernando Montoya, Bogotá, 2008), pp. 256-258. Para consultar la citada norma procesal véase http://www.legifrance.gouv.fr/affichCode.do?cidTexte=LEGI TEXT000006071154 [sitio visitado el 5 de junio de 2011].

${ }^{5}$ Figueroa, cit. (n. 3), p. 240; Alessandri, cit. (n. 1), p. 417; Suescún Melo, Jorge, Derecho privado. Estudios de derecho civil y comercial contemporáneo (2a edición, Bogotá, 2003), pp. 189 y 190. Este sistema era el que se contemplaba en el derecho romano, el cual consideraba a la víctima como un verdadero cómplice en el ilícito, motivo por el cual se le prohibía exigir la reparación de los perjuicios experimentados. ColomBo, Leonardo, Culpa aquiliana (Buenos Aires, 1947), pp. 205 y 206. 
afectado fuera la causa exclusiva o, al menos, determinante en la generación de los daños, pudiendo éstos imputarse sólo al actuar descuidado del mismo perjudicado, quien habrá absorbido el total de la causalidad ${ }^{6}$.

Se trata de un escenario distinto. El daño experimentado encuentra su origen tanto en la actividad del demandado como en aquella acción u omisión negligente de la propia víctima, configurando un fenómeno de concausas. En otros términos, el daño es el resultado coetáneo de ambos sujetos, aunque con intensidades diversas. $Y$ es en virtud de esta participación convergente de ambos involucrados en el ilícito, que se procede a rebajar la cuantía del resarcimiento ${ }^{7}$.

El cambio en la apreciación del daño encuentra su fundamento en la imprudencia de la víctima, cuya culpa debiera ser analizada conforme a los mismos parámetros que se utilizan en la evaluación de la negligencia del autor del daño.

El deber de cuidado respecto de los demás también se aplicaría a la víctima para sí misma y respondería, de igual manera, a la necesidad de conducirse con la prudencia que los hombres emplean ordinariamente en sus actos o negocios, tanto en sus acciones como en sus omisiones ${ }^{8}$.

Aun cuando calificar esta exigencia de autocuidado como un genuino d e $\mathrm{b}$ e $\mathrm{r}$ ha sido cuestionada, prefiriéndose para su denominación la expresión de c a r g a existe consenso en requerirla de quien ha resultado lesionado en sus intereses: un comportamiento que en forma razonable observaría una persona juiciosa que se preocupa por su propia seguridad'.

${ }^{6}$ Barros, cit. (n. 2), pp. 436-438; Alessandri, cit. (n. 1), pp. 414, 415 y 446449; Corral, cit. (n. 1), pp. 200 y 201; Diez, cit. (n. 1), pp. 225 y 226; Suescún, cit. (n. 5), pp. 169-171; López Mesa, Marcelo - Trigo Represas, Félix, Tratado de la responsabilidad civil. Cuantificación del daño (Buenos Aires, 2006), pp. 693-695. Así también se afirma que si la culpa de la víctima presenta las mismas características de la fuerza mayor respecto del agente, se alzará como la causa exclusiva del daño y el demandado debiera ser eximido de responsabilidad. Le Tourneau, Philippe, La responsabilité civile (2a edición, Paris, 1976), pp. 225-228.

${ }^{7}$ Alterini, Atilio Aníbal, Contornos actuales de la responsabilidad civil (Buenos Aires, 1987), p. 48; Alessandri, cit. (n. 1), pp. 415 y 416; Corral, cit. (n. 1), pp. 201 у 202; Соцомво, cit. (n. 5), pp. 204-206, quien utiliza la nomenclatura c u l p a concurrente o concurso de culpas. Lajurisprudencia es abundante en este sentido. Manifestaciones de esta consideración pueden encontrarse en Corte de Apelaciones de Santiago, 29 de marzo de 2011, número de ingreso 2.098-2010, número identificador Legal Publishing 48524; Corte Suprema, 15 de diciembre de 2009, número de ingreso 3.345-2008, número identificador Legal Publishing 42933.

${ }^{8}$ Alessandri, cit (n. 1), p. 412 y 413, Barros, cit. (n. 2), p. 431.

${ }^{9}$ La noción de $\mathrm{d}$ e b e $\mathrm{r}$ no respondería a una conducta que se exija a la víctima respecto de sí misma, sino que implicaría una necesaria relación de alteridad, en que ella se conecta con el tercero a quien pretende responsabilizar. Por el contrario, la c a r g a 
Esta perspectiva toma en cuenta el carácter subjetivo que posee el sistema de responsabilidad civil ${ }^{10}$, el cual exige un error de conducta por parte del agraviado y, tal como sucede con el autor del daño, formula un juicio de reproche a su comportamiento, comparando el proceder concreto del agente, con un modelo abstracto de diligencia que debió ser practicado. En cierta medida la construcción del deber de autocuidado que justifica la aplicación del artículo 2330 del Código civil se construye en formas análoga a la culpa imputable al victimario. Lo que no ha sido todavía afirmado con determinación es si también debiera aplicarse la teoría de la culpa infraccional o, incluso, para aquellos que estiman que la regla del artículo 2329 del Código civil consagra una presunción de culpa por el hecho propio, que permitiría entender que la víctima que se dedica a actividades peligrosas debiera presumirse que actuó con negligencia ${ }^{11}$. Este análisis, realizado tanto al victimario como a la víctima, garantiza un tratamiento igualitario para quienes han concurrido con sus actuaciones a generar un daño indemnizable, permitiendo aplicar de manera correcta el principio que favorece la reparación del víctima, el cual queda circunscrito a situaciones en que exista duda respecto de la participación del demandante ${ }^{12}$.

no impone un comportamiento a quien ha sido agraviado, sino que constituye un requisito a su actividad que condicionará su derecho a ser indemnizada por el total de los daños experimentados. BARRos, cit. (n. 2), pp. 428 y 429.

${ }^{10}$ Para algunos, la consideración de la actividad de la víctima a efectos de apreciar la cuantía de la indemnización o, incluso, su procedencia misma, es una manifestación que hace recordar la consagración de un sistema subjetivo de responsabilidad construido sobre la base de la culpa y que poco a poco a tomado notorios ribetes de objetivación: "[...] debe asumirse que en un sistema así la culpa de la víctima es la llave de corte del sistema, que de otro modo no sería de responsabilidad civil sino de causalidad material". López, Trigo, cit. (n. 6), p. 694. Es así como la noción de i n d i f e r e n c i a d e la $\mathrm{co} \mathrm{n} \mathrm{c} \mathrm{a} \mathrm{u} \mathrm{s} \mathrm{a,} \mathrm{que} \mathrm{permite} \mathrm{a} \mathrm{quien} \mathrm{incide} \mathrm{con} \mathrm{su} \mathrm{comportamiento} \mathrm{exigir} \mathrm{el} \mathrm{perjuicio}$ en su totalidad, sólo se reserva para determinadas hipótesis, tan específicas como los daños nucleares o aquellos provocados por productos, sin poder sostenerse una verdadera generalización de este concepto. Alterini, cit. (n. 7), pp. 47 y 48.

${ }^{11}$ Suescún, cit. (n. 5), pp. 174 y 175, 178 y 179; Mazeaud, Henri et Léon, Traité théorique et pratique de la responsabilité civile délictuelle et contractuelle ( $4^{\mathrm{a}}$ edición, Paris, 1949), pp. 376-378. De forma similar a lo que ocurre respecto de la c u l p a i n f r a c c i o n a l del autor del daño, el juicio de reproche y la acreditación de la negligencia del perjudicado se simplifican considerablemente si éste incurrió en alguna contravención a normas legales o reglamentarias. CORRAL, cit. (n. 1), pp. 203 y 204; BARros, cit. (n. 2), pp. 430 y 431. En este sentido, Corte Suprema, 24 de noviembre de 2010, número de ingreso 1.750-2009, número identificador Legal Publishing 46909.

${ }^{12}$ López, Trigo, cit. (n. 6), pp. 723 y 724; Barros, cit. (n. 2), p. 429. 


\section{LA CUANTÍA DE LA REBAJA}

Este juicio de reproche que se efectúa a la actuación de la víctima, permitirá verificar la concurrencia de su culpa como una de las causas que provocaron el daño por ella experimentado, haciendo aplicable el artículo 2330 CC. Y si bien la negligencia de quien resultó agraviado es un requisito reconocido para la rebaja en la apreciación de la indemnización, la complejidad surge al cuantificar esta reducción.

Es posible identificar sistemas que intentan medir la disminución del resarcimiento de acuerdo con la gravedad de la culpa. La reducción de la indemnización se efectúa sobre la base del mayor o menor reparo que pueda hacerse, distribuyendo la negligencia en proporción a la seriedad de los comportamientos. Para sus adherentes, este método evitaría el inconveniente que apareja la división mediante el recurso a la causalidad, pues, de utilizarse la teoría de la equivalencia de las condiciones, necesariamente debe concluirse que a ambos involucrados les correspondería asumir la mitad del daño, por cuanto cada uno de ellos concretó una causa necesaria en la producción del mismo ${ }^{13}$.

Esta propuesta ha sido objeto de críticas, pues transforma a la rebaja de la indemnización en una pena privada que sanciona la conducta impruden$\mathrm{te}^{14}$, dando lugar a los llamados "punitive damages", desconocidos hasta el momento para la tradición civil continental y ajenos al fin primordial que actualmente persigue el sistema de responsabilidad, cual es, obtener la satisfacción de la víctima del perjuicio ${ }^{15}$. Habría que agregar que no resulta apropiado cuantificar la rebaja en proporción a la intensidad de la culpa - tarea por sí difícil- si coincidimos en la posibilidad que haya una actividad culpable de la víctima reprochable en gran medida pero que no haya tenido una consecuencia importante en la realización del daño; y por otro lado, es aún posible que la culpa sea a penas perceptible para calificarla como tal, pero haya sido significativa en la generación del perjuicio.

Es por ello que se han buscado nuevas formas para determinar la rebaja, que la fundan en la causalidad. Para esta postura, la situación en estudio da lugar a una merma en la indemnización con independencia de la mayor o

${ }^{13}$ Mazeaud, cit. (n. 11), pp. 430-433.

${ }^{14}$ SuEsCún, cit. (n. 5), pp. 186 y 187; MAZEAUd, cit. (n. 11), p. 431.

${ }^{15}$ Viney, cit. (n. 4), pp. 222 y 223; Larraín PÁez, Cristián, Aproximación a los "punitive damages", en Pizarro Wilson, Carlos (coordinador), Estudios de derecho civil IV (Santiago, 2009), pp. 707-719. En cuanto las funciones que se atribuyen a la responsabilidad civil y las finalidades que ésta busca, véase: TunC, André, La responsabilité civile (2a edición Paris, 1989), pp. 133-155. 
menor gravedad de las culpas de los implicados ${ }^{16}$, la que no incidirá tampoco en la cuantía de la reducción; ésta se determinará recurriendo sólo a la relevancia causal que la actividad de la víctima tuvo en el daño. A partir de la imputación objetiva de aquel, será factible afinar los resultados que arrojaría la sola aplicación de la teoría de la equivalencia de las condiciones, delimitando el grado de influencia que en el perjuicio tuvo el autor y la víctima. Esta determinación de la relevancia causal, será el resultado de un análisis en que se evalúan ambas actividades, estableciendo cuál constituye la causa que ha maximizado las posibilidades de generación de los perjuicios, lo que permitirá proceder al cálculo de la injerencia que cada una ha tenido en la gestación de ellos ${ }^{17}$.

Como suele suceder existe una teoría ecléctica en que la utilización de estos métodos termina por realizarse en forma conjunta, debiendo el juez apreciar y valorar las respectivas faltas, procediendo con posterioridad a la determinación de la rebaja mediante la incidencia que por vía causal ellas han tenido en el ilícito ${ }^{18}$.

En nuestra opinión se trata sólo de un problema de causalidad, lo que arrastra auscultar en qué medida, sólo cuasal, la conducta de la víctima ha contribuido al perjuicio. Es cierto que conforme al artículo se requiere que la calificación de dicha conducta sea considerada culpable, pero eso no repercute en la cuantificación de la rebaja, sino que sólo es un elemento necesario para que la rebaja proceda, conforme al artículo $2330 \mathrm{CC}$.

Si bien la solución teórica considera la causalidad, pudiendo exigirse al victimario la indemnización sólo de aquel daño que ocasionó, no siéndole obligatorio pagar un daño cuyo irigen está en la propia víctima, lo cierto es

${ }^{16}$ Alessandri, cit. (n. 1), p. 415.

${ }^{17}$ Barros, cit. (n. 2), pp. 435 y 436.

${ }^{18}$ BARros, cit. (n. 2), p. 436 y en este mismo sentido, sentencia de la Corte de Apelaciones de Valparaíso, 28 de marzo de 2008, número de ingreso 1.276-2007, confirmada por la Corte Suprema, 15 de septiembre de 2008, número de ingreso 2.6972008, número identificador Legal-Publishing 41733. Un método distinto es posible identificar en el derecho norteamericano, el cual asienta la doctrina de la c o m p a r a c i ó n d e n e glige n c i as, utilizada como defensa de demandado cuando éste puede acreditar que el perjudicado ha colaborado en la producción del daño con sus propias acciones. Inicialmente llamada $\mathrm{n}$ e g lige n c i a cont ribut iva ("contributory negligence"), hoy se le conoce bajo la denominación de n e gl i g e n c i a c o m parat i v a ("comparative negligence") y busca determinar el monto de los perjuicios de acuerdo con el descuido en que hubieren incurrido las partes. En este sentido, su aplicación variará desde su ejercicio puro, en que el demandante sólo podrá alegar aquel porcentaje de daño en el que no participó, hasta su utilización con ciertas modificaciones, caso en el cual no podría requerir indemnización alguna si concurrió en un $50 \%$ o más de la negligencia total. Scheb, John M. - Scheb II, John M., An Introduction to the American Legal System (New York, 2002), p. 164. 
que en la práctica la rebaja es una cuestión más bien prudencial de los jueces o si se quiere entregada a la equidad de los magistrados quienes según las circunatancias evaluarán la cantidad a rebajar.

La lectura exclusiva desde la causalidad tiene, al menos, dos consecuencias. Al discutir la procedencia del artículo 2330 CC., la culpa de la víctima, entendida como un comportamiento reñido con lo que habría hecho un sujeto diligente, sólo refiere a un elemento de aplicación del precepto, sin ninguna incidencia respecto a la rebaja de la cuantía en la indemnización. En segundo término, al interrogarse por el quantum de la rebaja, debe circunscribirse el análisis a un problema de causalidad. En qué medida la conducta de la víctima causó su propio daño. No parece sensato aplicar aquí la equivalencia de las condiciones, cuya estructura límpida, pero tosca, nos llevaría nada más a repartir en partes iguales la rebaja. Es necesario aplicar teorías que convoquen la apreciación de la conducta conforme a parámetros flexibles vinculados a la previsibilidad y la razonabilidad, ya sea por vía de la causalidad adecuada o alguna de las manifestaciones de la imputación objetiva. En último término, entender la exposición imprudente de la víctima al daño como un problema causal, refuerza la idea que dicho elemento de la responsabilidad civil es normativo y no sólo una cuestión de hecho, siendo procedente la casación en el fondo por infracción al artículo 2330 CC.

\section{EL HECHO DE LAS VÍCTIMAS INCAPACES}

En caso que la víctima sea un incapaz, por esta condición, se excluye el artículo 2330 CC. ${ }^{19}$. La víctima no se encuentra en condiciones de representarse las consecuencias de sus actos, al no dominar el curso causal de éstos y, por ende, tampoco tendrá la posibilidad de ponderar sus actuaciones y evitar aquellas que son imprudentes. En términos más simples, el incapaz no puede actuar de manera culpable, o no puede ejercer un autocuidado, lo que excluye la posibilidad de cumplir con el elemento del "actuar negligente" exigido por el artículo 2330 CC. El juicio de reproche inicial que se efectúa para evaluar si el afectado se adecuó o no al estándar de cuidado que una persona razonable tendría consigo mismo, implica exceptuar de la norma en estudio

\footnotetext{
${ }^{19}$ Alessandri, cit. (n. 1), p. 416; Le Tourneau, cit. (n. 6), p. 230. De esta forma, el incapaz podrá aspirar a una reparación total por los daños causados por el tercero, sin perjuicio de hacer efectiva también la responsabilidad de sus cuidadores si éstos fueron negligentes en su deber de vigilancia, los cuales no podrán oponer el hecho de la víctima para obtener una rebaja, pues éste les es plenamente imputable. MAZEAUd, cit. (n. 11), p. $375, \mathrm{~N}^{\circ} 1461$, nota 2.
} 
a quienes se consideran como incapaces, conforme al artículo 2319 CC. ${ }^{20}$ o que hayan sido declarados como tales por resolución judicial.

Es cierto que algunos abogan por la aplicación irrestricta de la regla contenida en el artículo 2330. Señalan que la culpa de quien ha sido agraviado no constituye un verdadero juicio de reproche, sino que se trata de una especie de inoponibilidad que puede hacer valer el demandado en el juicio de atribución del daño. Para desprenderse de aquella parte de la indemnización en que no concurrió con su negligencia al haber intervenido causalmente la actividad de la víctima ${ }^{21}$. En todo caso, se reconoce que esta alegación no sería aceptable si el tercero, conociendo o debiendo advertir el estado del incapaz, haya podido prever que el comportamiento de este último, junto con su propio hecho, causarían un daño ${ }^{22}$.

En otros sistemas legales se ha instaurado la legitimación pasiva de los incapaces en sede de responsabilidad civil. Así ocurre en Francia luego de una evolución jurisprudencial, con reconocimiento legislativo posterior ${ }^{23}$.

${ }^{20}$ Diez, cit. (n. 1), pp. 228 y 229.

${ }^{21}$ Barros, cit. (n. 2), p. 434; Corral, cit. (n. 1), p. 203.

${ }^{22}$ Mazeaud, cit. (n. 11), pp. 378 y 379 . El sistema estadounidense contempla otra clase de criterios. Históricamente a los niños se les hacía responsables de los daños por ellos cometidos; sin embargo, algunas Cortes exceptúan de esta regla a los menores de siete años. Dado que la propia ley reconoce su incapacidad para cumplir con el deber de cuidado de un adulto, es que se realiza un análisis subjetivo de lo que sería una conducta razonable para ese niño, considerando su edad, inteligencia y experiencia, comparándolo con un modelo de autor menor de edad. No obstante, si el involucrado realiza actividades de adultos, las Cortes generalmente le aplicarán el estándar de éstos. Por otra parte, se distingue el caso de quienes padecen de discapacidades físicas, pues respecto de ellos se reconoce que es posible no alcanzar el requisito de actuar como una persona prudente; con todo, los involucrados deberán comportarse de acuerdo con el estándar de un sujeto razonable con las mismas incapacidades y no habrán de tomar riesgos irracionales. Por el contrario, aquellos que sufren deficiencias mentales y emocionales o que por una intoxicación voluntaria no sean capaces de actuar como una persona plenamente capaz, son generalmente sometidos al estándar del individuo prudente. Aquí se produce un balance entre los derechos del demandante que ha sufrido los daños y el demandado, cuya discapacidad pudo haber contribuido como factor en las pérdidas de la víctima. SCHEB - SCHEB, cit. (n. 18), pp. 161-162.

${ }^{23}$ Hasta 1984, la facultad de discernimiento del autor del acto se consideró el elemento subjetivo o moral que integraba la culpa y que la calificaba como tal. A partir de ese año y con sustento en las decisiones de la Asamblea plenaria de la Corte de casación, la culpa se redujo a su componente objetivo, es decir, ella opera simplemente en la medida en que se produzca la transgresión de una obligación determinada o de un deber de comportamiento general. La eliminación del elemento subjetivo alcanza a las faltas de las víctimas incapaces y los hace responsables por sus actos; lo anterior, se extiende también a aquellos casos en que ellos mismos sean los afectados, aplicándoseles la reducción en la indemnización si hubo una exposición a los perjuicios experimentados. 
En Chile, existe certeza sobre la necesidad que el demandado sea una persona capaz, lo que impide la aplicación del artículo 2330 CC. a los incapaces, quienes no son susceptibles de culpa, lo que es un elemento imprescindible para la procedencia de la exposición imprudente al daño.

¿Excluye esta circunstancia una rebaja en la indemnización? No parece adecuado entenderlo de esta manera. Si un incapaz ha ocasionado en parte su perjuicio, no existe una razón lógica que haga responsable al victimario de todo el daño. Otra vez es la causalidad la que debe resolver el problema, conforme al artículo $2314 \mathrm{CC}$. En este precepto se asienta el elemento de la causalidad, luego si el incapaz ha causado parte de su daño, el victimario sólo deberá responder de aquella parte que le resulta pertinente conforme a los parámetros de la causalidad. Si bien el artículo 2330 CC. es impertinente en la especie, no lo es la regla de causalidad. Entenderlo de otra forma implicaría un enriquecimiento injustificado para la víctima quien habiéndose causado en parte del perjuicio podría recolectar el total de la indemnización.

En forma concomitante a la participación de la víctima incapaz que se expuso al daño es posible que una o algunas víctimas por rebote hayan reclamado indemnización y, que a su turno, esas mismas víctimas, tuvieren a su cargo el cuidado de la víctima directa. Aquí cabría inclinarse por entender que respecto de estas víctimas por rebote resulta aplicable el artículo 2330 CC., quienes al no haber ejercido en forma adecuada el cuidado que les era exigible no podrán recibir el total de la indemnización.

Así, por ejemplo, la Corte Suprema: "este sentenciador concuerda con la posición del demandado en orden a la concurrencia de la causal de reducción prevista en el articulo 2330 CC.,pues los padres infringieron su deber de cuidado respecto a la menor al permitirle que escalara el techo del galpón donde conocian

Esta limitación en el resarcimiento es una consecuencia del rol causal que su falta tiene en la comisión del hecho y en realidad no obedece a la finalidad originaria de perseguir la reparación íntegra del agraviado. Por este motivo, la crítica a esta concepción es que, precisamente, la exclusión del factor subjetivo de la culpa termina por poner a la responsabilidad civil en contra de los propios perjudicados. Así, se señala que si el fin de protección de las víctimas justificó la abstracción de la facultad de discernimiento del autor, este mismo objetivo debiera ignorar los actos objetivamente ilícitos realizados por ellas si éstas carecen de capacidad, prescindiendo de la disminución en la indemnización, en aras de alcanzar la reparación integral de los daños. Este objetivo ha sido tenido en cuenta por la Corte de casación, toda vez que frente al rechazo a la reincorporación del elemento subjetivo de la culpa y con el fin de asegurar una reparación integral al incapaz, ha efectuado interpretaciones extensivas de ciertas nociones jurídicas, principalmente por la vía de descartar la influencia del hecho del agraviado en el vínculo causal que une a la actuación del tercero con el daño producido. BACACHEGibeili, Mireille - Larroumet Christian (director), Droit civil. Les obligations. La responsabilité civile extracontractuelle (Paris, 2007), V, pp. 488-490. 
de antemano que existía un trazado eléctrico a baja altura, pues son inquilinos del predio, por ende conocían a cabalidad los peligros a que se exponian sus hijos". Y agrega: "no podrá negarse la contribución directa que ha tenido a la ocurrencia del accidente, la acción temeraria e imprudente de la propia victima, además del descuido y negligencia inexcusable de los padres de la niña, quienes conocian sobradamente la existencia del tendido eléctrico que pasaba sobre el techo del galpón, y las graves consecuencias que son de esperar frente al eventual contacto de una persona con los cables energizados" 24 .

Una última consideración respecto a este asunto desde una perspectiva más práctica incide en relativizar el problema jurídico expuesto si se considera que la indemnización reclamada, de manera frecuente, es el daño moral, cuya rebaja en términos de exposición imprudente es bastante difusa.

\section{EL HECHO Y LA CULPA DE LA VÍCTIMA RESPECTO DE LOS HEREDEROS Y LAS VÍCTIMAS POR REPERCUSIÓN}

La culpa de quien ha resultado dañado podría tener influencia en el monto de reparación que pueden exigir sus herederos o cesionarios y las víctimas por repercusión.

Si quienes inician un proceso de indemnización de daños en contra del autor lo hacen en su calidad de causahabientes de la víctima que ha fallecido, la reducción de la suma final de reparación será procedente, siempre que ésta se haya expuesto en forma imprudente al daño. En virtud del principio de continuidad de la persona del causante, contenido en el artículo 1097 CC., la acción que correspondía al afectado se transmitirá a sus herederos con la misma deducción que podría haberle opuesto el tercero en vida ${ }^{25}$. Esta solución es lógica y justa, pues los demandantes requieren la indemnización que le habría correspondido al causante, no pudiendo quedar en una mejor posición.

En cambio, si quienes deducen una demanda indemnizatoria son las víctimas por repercusión y lo hacen en virtud de los daños propios que han experimentado, la procedencia del artículo 2330 CC. es discutida.

Se señala que la rebaja no les puede ser opuesta, pues ellas no se han expuesto en forma imprudente al daño que reclaman, el cual podrá ser material, si se produjo alguna pérdida económica que hayan debido soportar, o moral, si

\footnotetext{
${ }^{24}$ Corte Suprema, 7 de marzo de 2006.

${ }^{25}$ Alessandri, cit. (n. 1), p. 416; Diez, cit. (n. 1), pp. 236 y 237; Barros, cit. (n. 2), p. 438; MazeAud, cit. (11), pp. 380 et 381.
} 
el hecho ilícito ha provocado en ellas una afección psíquica o emocional provocada por los agravios o la muerte que ha padecido la víctima principal.

Se manifiestan algunas limitaciones de este enfoque. En caso que los demandantes, además de víctimas por rebote, reúnan la calidad de herederos, habiendo fallecido la víctima directa, no podrá exigirse el total de la indemnización si se hubiere aceptado la herencia del causante, quedando obligados al pago de las deudas hereditarias, entre las que se encuentra la reducción que el tercero tiene derecho a exigir del agraviado. Este enfoque, estricto desde la óptica del derecho sucesorio, lo es menos desde el derecho de las obligaciones, al no existir una deuda exigible antes de la respectiva sentencia que así lo reconozca. El argumento es artificioso e inútil. Se señala, también, que debiera mantenerse la rebaja si quienes reclaman un daño por repercusión tenían un deber de cuidado o vigilancia respecto de la victima principal, quien, por la desidia en el cuidado de sus custodios, resultó menoscabada. En este escenario, se entiende que existe una exposición negligente al perjuicio, pues tanto el tercero como ellos mismos han contribuido a la materialización final del hecho ilícito ${ }^{26}$. Tampoco parece convincente este argumento. Al encontrarse la víctimas por rebote en situación de cuidado de la víctima que se expuso con culpa al daño, no es que la rebaja no proceda, es sólo que el daño ocasionado, en parte, al menos, fue originado en la propia conducta del afectado directo, no pudiendo responsabilizarse, en esa parte, al victimario. Lo contrario infringiría las reglas de la causalidad.

La mención a la causalidad, en la crítica precedente, parece ser la opinión que soluciona el asunto. La injerencia causal que tuvo la conducta de la víctima directa en la generación del menoscabo que experimentan las víctimas por repercusión, permite evitar que el victimario termine pagando daños que no causó. En parte esos perjuicios fueron causados por la propia víctima directa y si en algo repercute en otros sujetos, mal podría reclamársele al victimario, siendo sólo posible, aunque de manera hipotética, que demandaran a la propia víctima principal en esa parte en que se expuso. Los distintos perjuicios a los afectados por rebote, tuvieron su origen en un contexto de concausas, en que participó tanto el tercero como la víctima principal, proporción que habrá de tenerse en cuenta para responsabilizar al demandado por los hechos que efectivamente cometió ${ }^{27}$.

\footnotetext{
${ }^{26}$ Alessandri, cit. (n. 1), pp. 416 y 417; Mazeaud, cit. (n. 11), pp. 380-382; Figueroa, cit. (n. 3), p. 246, nota 2.

${ }^{27}$ Barros, cit. (n. 2), pp. 438 y 439; Suescún, cit. (n. 5), pp. 190-194; Le TourNEAU, cit. (n. 6), p. 229; BACACHE-Gibeili, cit. (n. 23), pp. 369-371 et 486. Corte de Apelaciones de Concepción, 19 de julio de 2007, número de ingreso 2.882-2006, número identificador Legal Publishing 36674.
} 


\section{CONCLUSIONES}

1. El hecho de la víctima por lo general es una condición para consumar un ilícito civil; no obstante, usualmente éste no tiene relevancia al momento de determinar la indemnización que deberá ser entregada. Por el contrario, si su actividad culpable interviene en el vínculo causal, se producirá una hipótesis de concausas en la cual cabría aplicar la reducción proporcional en la apreciación del daño, contenida en el artículo 2330 CC.

2. La procedencia de esta norma queda determinada por la concurrencia de la actividad imprudente del perjudicado; sin embargo, en la determinación de la rebaja de la suma indemnizatoria, se tendrá en vista la relevancia causal que la acción de cada involucrado ha tenido en la producción del daño y, en la práctica, la solución es más bien cercana a la prudencia judicial.

3. La exposición imprudente del afectado no sólo fuerza a esta reducción en la indemnización que ella misma reclama, sino que también tendrá injerencia en aquellos montos demandados por sus herederos, si hubiere fallecido, o por las víctimas por repercusión, lo que es acertado en perspectiva causal.

\section{BIBLIOGRAFÍA}

Alessandri Rodríguez, Arturo, De la responsabilidad extracontractual en el derecho civil chileno (Santiago, 2005).

Alterini, Atilio Aníbal, Contornos actuales de la responsabilidad civil (Buenos Aires, 1987.

Bacache-Gibeili, Mireille - Larroumet Christian (director), Droit civil. Les obligations. La responsabilité civile extracontractuelle (Paris, 2007), V.

BARros Bourie, Enrique, Tratado de responsabilidad extracontractual (Santiago, 2009).

Colombo, Leonardo, Culpa aquiliana (Buenos Aires, 1947).

Corral Talciani, Hernán, Lecciones de responsabilidad civil extracontractual (Santiago, 2004).

Diez SChWerter, José Luis, El daño extracontractual. Jurisprudencia y doctrina (Santiago, 2002).

Domínguez Águila, R., El hecho de la victima como causal de exoneración de responsabilidad civil, en Revista de Derecho, 135 (Universidad de Concepción, 1966), p. 29 ss.

Figueroa Yáñez, Gonzalo (redactor), Código Civily leyes complementarias (2a edición, Santiago, 1998) $)^{2}$ X.

Larraín PÁez, Cristián, Aproximación a los "punitive damages", en Pizarro Wilson, Carlos (coordinador), Estudios de derecho civil IV (Santiago, 2009).

Le Tourneau, Philippe, La responsabilité civile (2a edición, Paris, 1976).

López Mesa, Marcelo - Trigo Represas, Félix, Tratado de la responsabilidad civil. Cuantificación del daño (Buenos Aires, 2006. 
Mazeaud, Henri et Léon, Traitéthéorique et pratique de la responsabilitécivile délictuelle et contractuelle (4a edición, Paris, 1949).

Pizarro Wilson, Carlos - De la Maza Gazmuri, Iñigo, Responsabilidad civil. Casos prácticos (5 edición, Santiago, 2010).

Scheb, John M. - Scheв II, John M., An Introduction to the American Legal System (New York, 2002).

Suescún Melo, Jorge, Derecho privado. Estudios de derecho civil y comercial contemporáneo ( $2^{a}$ edición, Bogotá, 2003).

Tunc, André, La responsabilité civile ( $2^{a}$ edición, Paris, 1989).

Viney, Geneviève, Tratado de derecho civil. Introducción a la responsabilidad (trad. cast. Fernando Montoya, Bogotá, 2008). 